\title{
WEBSITES DAS BIBLIOTECAS UNIVERSITÁRIAS COMO DISPOSITIVOS DE COMUNICAÇÃO E POTENCIALIZADORES DO ACESSO À INFORMAÇÃO
}

\section{Raquel do Rosário Santos}

Doutora em Ciência da Informação pela Universidade Federal da Paraíba.

Professora Assistente do Instituto de Ciência da Informação da Universidade Federal da Bahia.

E-mail: quelrosario@gmail.com

\section{Livia Santos de Freitas}

Mestre em Ciência da Informação pela Universidade Federal da Bahia. Bibliotecária da Universidade Federal da Bahia.

E-mail: freitas livia@hotmail.com

\section{Henriette Ferreira Gomes}

Doutora em Educação pela

Universidade Federal da Bahia.

Professora Titular do Instituto de

Ciência da Informação e do Programa

de Pós-graduação em Ciência da

Informação da Universidade Federal da Bahia.

E-mail: henriettefgomes@gmail.com

\section{RESUMO}

As bibliotecas universitárias têm buscado se aproximar de seus usuários efetivos e potenciais e, para tal, vem utilizando recursos de comunicação no espaço virtual, disponibilizados em seus websites ou páginas. Nesse sentido, esse artigo teve como objetivo identificar e analisar se e como as bibliotecas centrais e/ou sistemas de bibliotecas das universidades federais e estaduais da Região Nordeste do Brasil têm desenvolvido os seus websites ou páginas e se esses espaços têm a possibilidade de ampliar ações de comunicação e do acesso à informação. 0 estudo teve por método o levantamento, associado ao método de estudos de casos múltiplos e utilizou a abordagem quantitativa como procedimento de análise de dados. Como resultado, identificou-se que grande parte das bibliotecas centrais e/ou sistemas de bibliotecas das universidades federais e estaduais têm desenvolvido seus websites ou páginas buscando ampliar os canais de comunicação e de acesso à informação, através do uso de dispositivos de comunicação tradicionais e aqueles próprios da web social, assim como da apresentação e disponibilização de diversos serviços. Contudo, embora as bibliotecas universitárias tenham avançado, em alguma medida, sobre o uso dos dispositivos de informação e a prestação de serviços há a necessidade dessas repensarem não somente as suas atividades cotidianas, mas, sobretudo, como interagem com os seus usuários na esfera do espaço virtual, visto que este ainda se apresenta limitado, dificultando ou impossibilitando ao usuário conhecer e usufruir das potencialidades que esse ambiente bem planejado pode oferecer.

Palavras-chave: Bibliotecas universitárias. Acesso à informação. Websites - Bibliotecas universitárias.

WEBSITES OF LIBRARIES UNIVERSITY AS DEVICES AND COMMUNICATION IMPROVERS OF ACCESS TO INFORMATION 


\begin{abstract}
University libraries have sought to approach their actual and potential users and to this end have been using communication resources in the virtual space available on their websites or pages. Thus, this article aims to identify and analyze whether and how the core libraries and / or library systems of federal and state universities in the Northeast of Brazil have developed their websites or pages and these spaces have the possibility of expanding actions of communication and access to information. The study was the survey method associated with the method of multiple case studies and used a quantitative approach to data analysis procedure. As a result, it was found that most of the core libraries and / or the federal and state universities library systems have developed their websites or pages seeking to expand the channels of communication and access to information through the traditional use of communication devices and those own social web, as well as the presentation and delivery of various services. However, while university libraries have advanced to some extent on the use of information devices and the provision of services for the need for these not only rethink their daily activities, but above all, how they interact with their users in the sphere of virtual space, as this still appears limited, making it difficult or impossible to user to meet and take advantage of the potential that well-designed environment can offer.
\end{abstract}

Keywords: university libraries. Access to information. Websites - University libraries.

\title{
1 INTRODUÇÃO
}

As bibliotecas universitárias têm como sua essência ser uma instituição capaz de subsidiar e apoiar o papel desempenhado pelos professores, pesquisadores e alunos no ensino, na aprendizagem e na pesquisa científica, visto que são essas atividades que impulsionam as descobertas e alimentam o desenvolvimento da ciência. E, o seu papel social reside em aproximar os sujeitos de tempos históricos diferentes, ou seja, produtores e consumidores de informação e, ao mesmo tempo, desenvolver atividades que possibilitem a esses sujeitos o acesso, o uso e apropriação da informação para benefício próprio, em prol de um crescimento cultural e intelectual.

Para cumprir tal papel, a biblioteca universitária vem, pouco a pouco, desenvolvendo ações para tornar o seu ambiente físico cada vez mais visível, inovador e reconhecido pelos usuários. Essa ação vem se desenvolvendo também por meio da web 
com a disponibilização de espaços virtuais, que potencializam a comunicação direta entre os profissionais que atuam na biblioteca e os usuários, promovendo assim o acesso confortável e confiável à informação.

Os websites das bibliotecas, como também os dispositivos de comunicação na web, devem ser utilizados de modo a conduzir os usuários a ampliar suas expectativas e visão quanto ao papel da biblioteca, como também a utilizarem esse espaço para interagir com outros sujeitos, produzindo informações e conhecimentos. Os websites ou as páginas das bibliotecas são espaços na web que oferecem informações confiáveis e de maneira confortável para os usuários, tanto os reais quanto os potenciais, representando, desta forma, o primeiro canal de comunicação e informação da biblioteca para além do ambiente físico. Assim, as bibliotecas universitárias devem desenvolver um espaço na web que atendam a demanda de informação dos usuários e seja também um aliado no processo de comunicação e interação com eles.

A partir dessa reflexão, justificou-se a realização deste estudo cujo problema consistiu em investigar se e como as bibliotecas universitárias vêm desenvolvendo os seus websites ou páginas para disponibilizar um espaço voltado à realização de ações de comunicação direta com seus usuários e potencializar o acesso à informação. A resposta a este problema de pesquisa teve como objetivo geral identificar e analisar se e como as bibliotecas centrais e/ou sistemas de bibliotecas das universidades federais e estaduais da Região Nordeste do Brasil têm desenvolvido os seus websites ou páginas e se esses espaços têm a possibilidade de ampliar ações de comunicação e do acesso à informação.

Para alcançar o objetivo deste estudo, se desenvolveu a observação direta e intensiva aos websites das bibliotecas centrais e/ou sistemas de bibliotecas das universidades federais e estaduais da Região Nordeste, associado ao método de estudos de casos múltiplos para verificação do modo como esses dispositivos vêm sendo usados no processo de comunicação e auxílio ao acesso e uso da informação.

\section{A BIBLIOTECA UNIVERSITÁRIA PARA ALÉM DOS SEUS MUROS FÍSICOS: uso do espaço virtual para aproximação entre usuários e biblioteca}

As bibliotecas universitárias possuem um amplo campo de atuação para ser trabalhado à luz da aprendizagem autônoma dos usuários, frente aos serviços e produtos 
de informação de forma democrática. Por meio dos serviços e produtos por elas desenvolvidos, oferecem oportunidade àqueles que se encontram em condições de desvantagem social e que, por caminhos diversos, tiveram acesso à universidade. Nessa perspectiva, Caregnato destaca o potencial da biblioteca universitária e do seu papel central no processo de ensino-aprendizagem:

Bibliotecas acadêmicas desempenham um papel central no processo educacional; além de apoiar a pesquisa, o ensino e o aprendizado através da provisão do acesso à informação, elas também devem oferecer serviços voltados para o aprendizado de métodos e técnicas de busca e uso da informação e exploração dos recursos informacionais, tanto para atividades relacionadas ao curso imediato de estudo quanto para as necessidades da vida profissional futura. (CAREGNATO, 2000, p. 48, grifo nosso).

A biblioteca universitária é considerada como ambiente ideal para a troca de saberes e experiências, pois busca auxiliar o sujeito a desenvolver e expandir seus saberes conceituais e procedimentais referentes à própria informação, dotando-o de capacidade para saber pesquisar, definir caminhos de busca, localizar, selecionar, organizar informações, avaliá-las e explorar os múltiplos recursos disponíveis. Para tanto, a biblioteca universitária oferece ao sujeito o seu acervo informacional em formato físico e eletrônico e este acervo, considerando que é o registro compartilhado do conhecimento acumulado, constitui-se na base utilizada pelo sujeito para a realização de suas atividades acadêmicas e de pesquisa.

As atividades de mediação desenvolvidas pela biblioteca universitária visam não somente a uma satisfação de necessidade de informação imediata, mas, além de tudo, auxiliar o sujeito na construção e desenvolvimento de habilidades e competências informacionais, para que o mesmo possa se apropriar de um domínio das fontes e dispositivos de informação. Nesse sentido, Almeida Júnior (2015, p.25) entende a mediação da informação como:

Toda ação de interferência - realizada em um processo, por um profissional da informação e na ambiência de equipamentos informacionais - direta ou indireta; consciente ou inconsciente; singular ou plural; individual ou coletiva; visando a apropriação de informação que satisfaça, parcialmente e de maneira momentânea, uma necessidade informacional, gerando conflitos e novas necessidades informacionais. 
A mediação da informação se desenvolve em toda atividade biblioteconômica, não apenas naquelas que mais diretamente proporcionam o acesso à informação, mas, em todo o processo que favorece que essa informação chegue até o usuário, potencializando o uso e a apropriação dessa informação. As atividades de mediação da informação podem ser as mais diversas possíveis, incluindo práticas que incentivem o hábito de leitura, escrita e pesquisa - mediação direta da informação - que dotarão o sujeito de recursos cognitivos e socioculturais para que venha lidar com a informação em toda a sua complexidade e alcançar o que Perroti e Verdini (2008) denominam de aprendizagens informacionais.

Para que a biblioteca alcance com êxito o cumprimento de seu papel enquanto colaboradora para o processo de ensino-aprendizagem, é indispensável que ela produza e compartilhe com sua comunidade práticas voltadas para o acesso, busca e utilização de seus dispositivos informacionais. Essas práticas devem ser realizadas visando, sobretudo, o benefício do usuário e a satisfação da sua necessidade de informação e, para tanto, o bibliotecário deve lançar mão da mediação da informação.

O processo de aprendizagem depende profundamente do ambiente social no qual o sujeito está inserido, segundo a concepção socioconstrutivista de Vygotsky (1991). Entretanto, este ambiente, na atualidade, está imerso nas tecnologias da informação e comunicação digitais e essa nova realidade de equipamentos, produtos, serviços e conteúdos digitais trazem para a biblioteca universitária a preocupação em acompanhar esses avanços para continuar servindo a sua comunidade.

A biblioteca universitária, ao utilizar e explorar os recursos na web, como o website, pode se aproximar dos seus usuários, apresentando informações sobre o seu acervo, o seu ambiente físico, além de alternativas para contato e interação que possam tirar dúvidas, indicar problemas ou sugestões. Ao realizar essa ação, a biblioteca estará contribuindo com os sujeitos, oferecendo um conforto no acesso a informação e a possibilidade desses serem participantes no seu desenvolvimento.

0 moderno profissional da informação deve antever as mudanças nos canais de distribuição de informação e é necessário que ele esteja preparado para esses novos canais de distribuição da informação. A partir dessa percepção, modifica-se a forma e o meio de mediar, adequando-se e desenvolvendo modelos eficazes para atender às novas realidades. (VALENTIM, 2000, p. 20). 
Ao atuar proativamente, utilizando os espaços virtuais e recursos de comunicação, a biblioteca também amplia a possibilidade de um número maior de usuários reconhecer a relevância do seu papel para sociedade, como ambiente de esclarecimento de suas dúvidas e como colaboradora na ampliação do seu conhecimento. Nesse sentido, Aguiar (2012, p. 108) afirma que "[...] a biblioteca precisa estar onde o usuário está, falar a linguagem da Geração Y e se comunicar por canais diferentes dos tradicionais, ofertando novos serviços e produtos, juntamente com os já existentes $(e$ mail, telefone, formulários etc.)."

Os espaços virtuais da biblioteca, como também os recursos de comunicação da web social disponibilizados por ela devem ser entendidos como fortes aliados que favorecem a ampliação de debates, compartilhamento de informações, entre outras atividades que promovam a interação entre os sujeitos e deles com a informação e a biblioteca.

Conforme Melo, Marques e Pinho (2014, p.77), “[...] o bibliotecário necessita desenvolver meios para tornar a biblioteca atraente e indispensável, utilizando-se das tecnologias para atribuir valor à unidade, uma vez que os usuários tendem a distanciarse da biblioteca física ao utilizar a internet.” Na realização das atividades, produtos e serviços informacionais, o bibliotecário deve se aproximar do usuário e manter com ele uma interação, para que possa estabelecer uma comunicação continuada, de modo que seja possível apoiar, auxiliar, mediar, enfim, realizar algum tipo de interferência para o desenvolvimento dos usuários.

A biblioteca universitária poderá adotar um perfil proativo em relação a uma colaboração mais ativa dos seus usuários, tanto na perspectiva de atender às necessidades individuais de cada sujeito quanto de fortalecer uma participação coletiva, com troca, debate e produção coletiva de ideias e desenvolvimento de atividades.

Se antes a web era estruturada por meio de sites que colocavam todo o conteúdo on-line, de maneira estática, sem oferecer a possibilidade de interação aos internautas, agora é possível criar uma conexão por meio das comunidades de usuários com interesses em comum, resultado do uso da plataforma mais aberta e dinâmica (BLATTMANN; SILVA, 2007, p. 199, destaque nosso).

Os recursos de comunicação na web promovem uma nova maneira de interação os sujeitos podem se comunicar no tempo em que desejarem, independentemente da 
distância geográfica que podem separá-los fisicamente. A “[...] Web 2.0 é um novo espaço para acessar, organizar, gerenciar, tratar e disseminar a informação, conhecimentos e saberes. [...] cabe estudar, experimentar, explorar tecnologias da Web 2.0 para facilitar o acesso e ampliar o uso da informação." (BLATTMANN; SILVA, 2007, p. 211). Então, é imprescindível que a biblioteca sistematize suas atividades de mediação da informação e adote as ações de gestão da informação e do conhecimento.

O bibliotecário pode adotar os recursos que a web social oferece, a fim de dinamizar a comunicação com os seus usuários. Curty (2008, p. 55) afirma que a web pode ser compreendida como

Uma web mais social, pois envolve mais pessoas; mais colaborativa, porque todos são partícipes potenciais e têm condição de se envolver mais densamente; mais apreensível, pois desmistifica que conhecimentos técnicos sejam necessários para a interação; uma web que se importa menos com a tecnologia de informação e mais com pessoas, conteúdo e acesso: dizem que por essa Web denota-se a versão 2.0.

Os dispositivos de comunicação da web social, como os espaços virtuais disponibilizados pelas bibliotecas, contribuem para um novo posicionamento do usuário, que passa a ter uma relação mais ativa com a informação, tanto na busca, no acesso e no uso da informação, quanto na produção de novos conhecimentos. Por meio desses recursos de comunicação na web, o usuário tem mais chances de acessar a informação, não apenas por estar na $w e b$, um espaço de grande quantidade de fontes de informação, mas também por receber a colaboração de outros sujeitos, que trocam e indicam informações relevantes.

Nesse sentido, a biblioteca deve intensificar a utilização e explorar mais ativamente os seus espaços virtuais nos quais os sujeitos, além de acessarem conteúdos, também possam produzir e disponibilizar suas informações, o que poderá ressignificar as práticas dos bibliotecários e contribuir com o próprio processo de desenvolvimento dos usuários.

\section{PROCEDIMENTOS METODOLÓGICOS}

O problema estudado nesta pesquisa foi o de investigar se e como as bibliotecas universitárias vêm desenvolvendo os seus websites para disponibilizar um espaço 
voltado à realização de ações de comunicação direta com seus usuários e potencializar o acesso à informação.

Dessa maneira, este estudo teve como objetivo geral: identificar e analisar se e como as bibliotecas centrais e/ou sistemas de bibliotecas das universidades federais e estaduais da Região Nordeste do Brasil têm desenvolvido os seus websites e se esses espaços têm a possibilidade de ampliar ações de comunicação e do acesso à informação.

Para alcançar esse objetivo geral, foram traçados como objetivos específicos:

a) levantar quais os recursos de comunicação para/com os usuários disponíveis nos websites das bibliotecas universitárias federais e estaduais da Região Nordeste;

b) identificar se existem e quais os serviços disponibilizados aos usuários por meio dos websites dessas bibliotecas universitárias;

c) identificar se existem links ou informações que aproximem e/ou auxiliem os usuários para o acesso e uso às fontes de informação.

A pesquisa foi realizada através da adoção do método do levantamento para identificação dos websites das bibliotecas das universidades federais e estaduais da Região Nordeste do Brasil, associado ao método de estudos de casos múltiplos para verificação do modo como esses espaços vêm sendo disponibilizados para potencializar ações de comunicação e do acesso à informação.

No momento inicial da realização da coleta de dados, ocorrido no primeiro semestre de 2016, foi realizado um levantamento inicial para a identificação das bibliotecas das universidades federais e estaduais da Região Nordeste do Brasil e quais dessas disponibilizavam websites. Na segunda etapa da pesquisa, a partir da realização das visitas aos websites das bibliotecas universitárias foram identificados os recursos de comunicação disponíveis nos websites dessas bibliotecas.

Também se buscou identificar se existem e quais os serviços disponibilizados aos usuários por meio dos websites dessas bibliotecas universitárias e, por fim, se existem links ou informações que aproximem e/ou auxiliem os usuários para o acesso e uso às fontes de informação.

0 procedimento de análise de dados teve uma abordagem quantitativa, em cada uma das etapas da pesquisa foram tratados quantitativamente os dados, atividade que possibilitou, posteriormente, o desenvolvimento dos Gráficos apresentados na próxima seção deste trabalho. 


\section{APRESENTAÇÃo E DISCUSSÃO DOS RESULTADOS}

Como resultado do levantamento foram identificadas 16 bibliotecas centrais ou sistemas de bibliotecas nas universidades federais da Região Nordeste brasileira e 14 bibliotecas centrais ou sistemas de bibliotecas nas universidades estaduais. No âmbito das bibliotecas centrais ou sistemas de bibliotecas federais, verificou-se que das 16 bibliotecas encontradas todas possuem um endereço eletrônico que permite ao usuário visualizar os recursos online disponibilizados pelas bibliotecas. Contudo, das 16 bibliotecas analisadas, 15 direcionam o usuário para uma página ou um website com informações e serviços diversos, enquanto que 1 biblioteca tem como informação central e unívoca o seu catálogo online, conforme pode ser observado no Gráfico 1.

Gráfico 1- Bibliotecas centrais ou sistema de bibliotecas federais e estaduais e sua presença na web

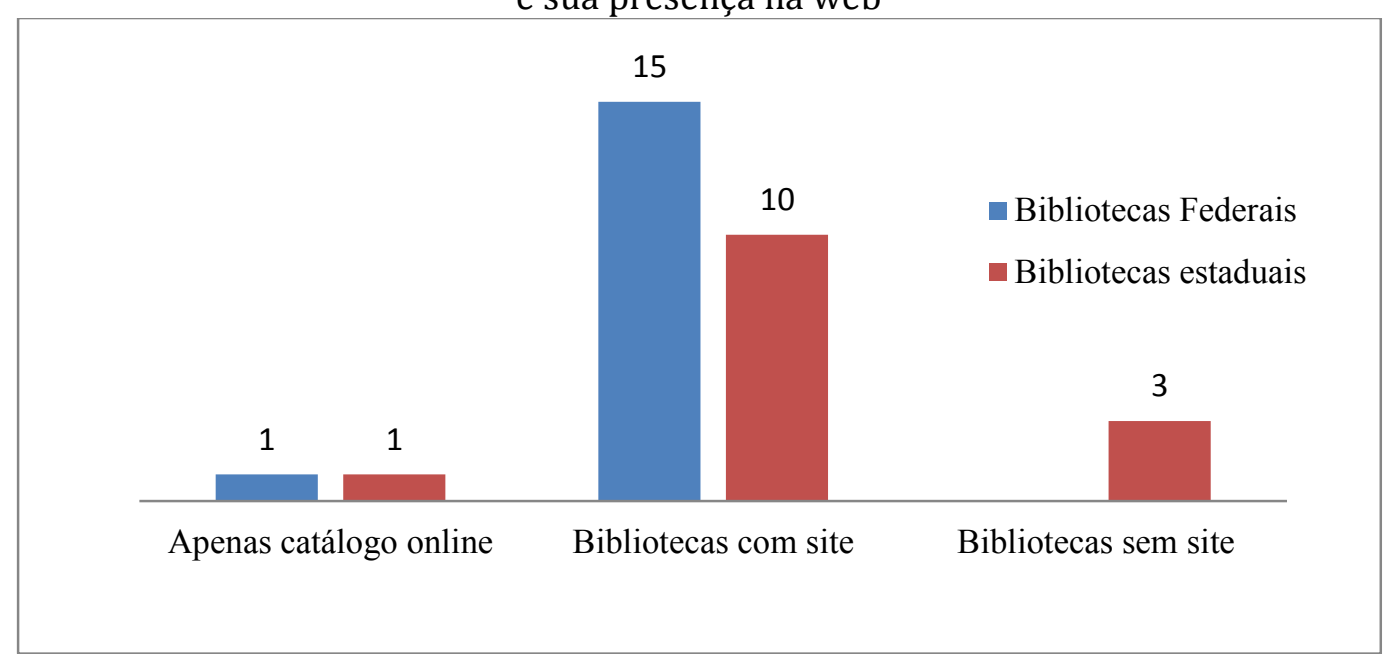

Fonte: Dados da pesquisa.

Ainda no que se refere ao Gráfico 1, pode-se constatar que, em nível estadual foram identificadas 14 bibliotecas centrais ou sistemas de bibliotecas, sendo que destas 10 possuem uma página ou um website com informações e serviços diversos, 3 delas não possuem um endereço eletrônico e 1 direciona o usuário para o catálogo online, sem nenhuma outra informação relacionada.

Como pode ser analisado, as bibliotecas centrais ou sistema de bibliotecas federais e estaduais tem buscado se apresentar de forma remota para os seus usuários, acentuadamente em um nível federal, e crescente para aquelas da esfera estadual denotando assim, uma atenção por parte dessas bibliotecas para demonstrar sua 
presença na web utilizando para isso os recursos das tecnologias de comunicação e informação.

Além da presença na $w e b$, as bibliotecas centrais ou sistema de bibliotecas federais e estaduais também tem buscado atender aos seus usuários nas mais diversas necessidades de informação, através dos recursos de comunicação denominados tradicionais e aqueles relacionados ao ambiente da web social. Esse resultado demonstra que as bibliotecas estão atentas ao que foi sinalizado por Valentim (2000), que destaca a necessidade do profissional da informação antever as mudanças dos canais de acesso à informação e adotar novas ações e atividades de mediação da informação para atender adequadamente aos seus usuários, sem perder de vista as mudanças do meio, adaptando assim, a forma de mediar.

Nesse sentido, das 16 bibliotecas centrais ou sistema de bibliotecas federais, 14 têm o e-mail como um dos meios de comunicação entre estas e seus usuários, já o contato via telefone, através da disponibilização dos números de unidades de bibliotecas e setores específicos configuraram entre 13 das 16 bibliotecas federais estudadas, conforme apresentados no Gráfico 2.

Gráfico 2 - Recursos de comunicação tradicionais utilizados pelas bibliotecas centrais ou sistema de bibliotecas federais e estaduais

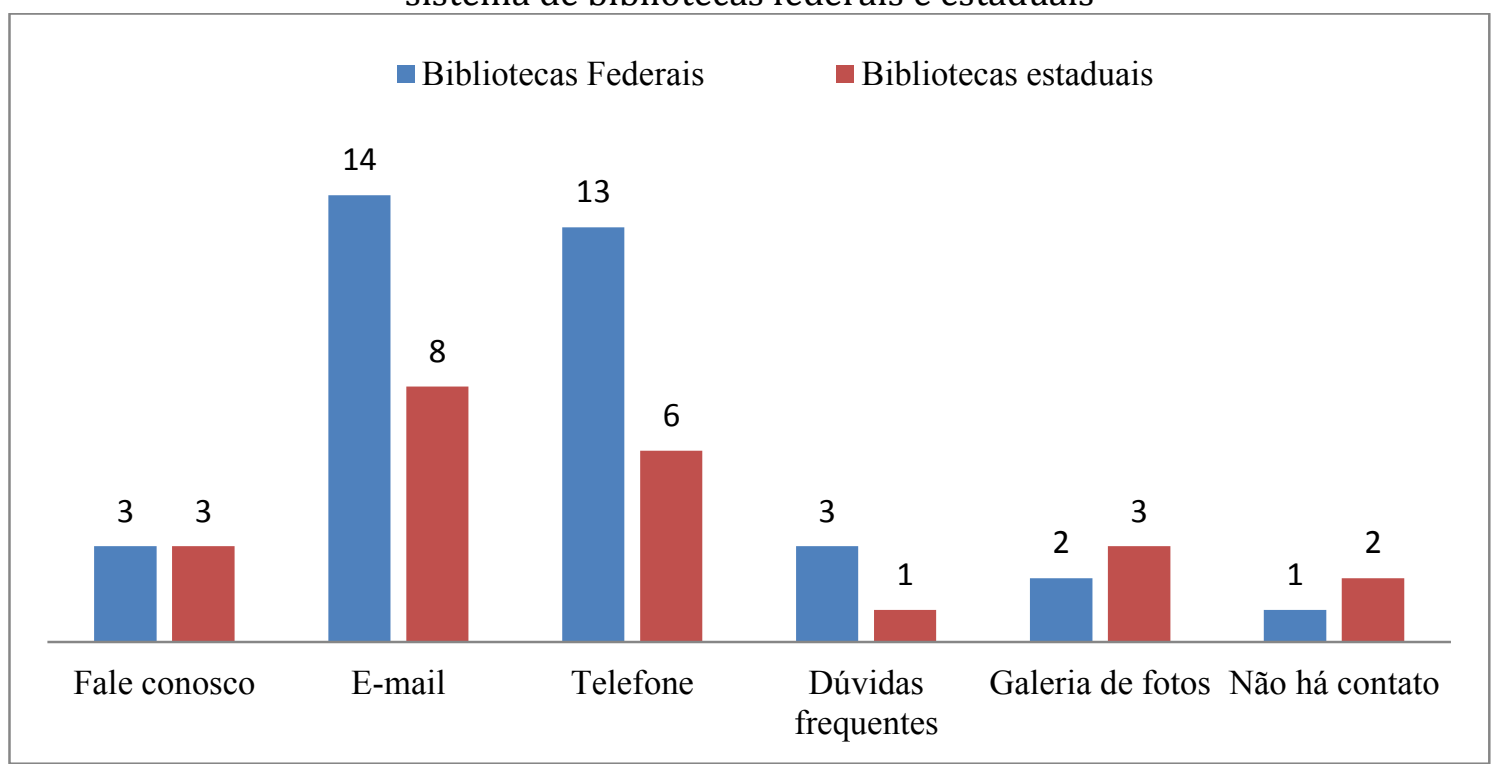

Fonte: Dados da pesquisa.

Ainda de acordo com o exposto no Gráfico 2, verificou-se que 3 das 16 bibliotecas centrais ou sistema de bibliotecas federais estudadas utilizam do recurso de "dúvidas frequentes" para tentar sanar as necessidades de informação mais recorrentes por parte 
dos usuários, seguido pelo recurso de comunicação "fale conosco", com 3 registros entre as bibliotecas federais, no qual é disponibilizado um formulário de preenchimento para que o usuário possa se expressar, assim como a galeria de fotos, encontrado em 2 bibliotecas centrais ou sistema de bibliotecas federais.

Nas bibliotecas centrais ou sistema de bibliotecas estaduais, das 14 estudadas 8 disponibilizam o recurso do e-mail para que os usuários possam estabelecer comunicação com a biblioteca central ou um de seus setores e unidades de funcionamento. Apesar de o e-mail ser um recurso de comunicação já bastante difundido na Sociedade da Informação, chegando inclusive a ser classificado nesta pesquisa como um recurso tradicional, identificou-se que ainda existem bibliotecas centrais ou sistema de bibliotecas estaduais que não disponibilizam esse recurso, conforme pode ser verificado no Gráfico 2, resultado que se assemelha aos obtidos juntos às bibliotecas centrais ou sistema de bibliotecas federais.

Dado que também demanda atenção diz respeito ao número de bibliotecas centrais ou sistema de bibliotecas estaduais que disponibilizam o contato telefônico como recurso de comunicação entre esta e seus usuários, sendo que das 14 bibliotecas estudadas apenas 6 apresentam essa informação. Tais resultados permitem inferir que não está sendo dada a devida atenção aos recursos de comunicação disponibilizados aos usuários para que estes possam estabelecer interlocução com suas bibliotecas.

Os demais recursos de comunicação como "fale conosco" e galeria de fotos tiveram 3 ocorrências entre as bibliotecas estaduais estudadas, dados esses que se aproximam da realidade das bibliotecas federais.

Na atualidade, muitas bibliotecas têm buscado estabelecer uma interlocução mais efetiva com os seus usuários e para tal vêm utilizando os recursos oferecidos pela web social como o facebook, twitter, instagram, e outros. Esse resultado se assemelha ao pensamento de Aguiar (2012) quando este pontua sobre a necessidade dos bibliotecários adotarem novos recursos de comunicação e informação para se aproximarem de seus usuários, interagindo através da linguagem e dos recursos comuns a essa comunidade. 0 autor ainda destaca que esses recursos devem ir além dos já existentes, como exemplo, o $e$-mail, telefone, entre outros, todavia, nesta pesquisa verificou-se que ainda existe uma deficiência na disponibilização dessas tecnologias ditas tradicionais. Esse resultado sinaliza a necessidade dos bibliotecários avaliarem a disponibilização dos recursos de comunicação e iniciar pelas tecnologias mais acessíveis e usuais de todo sujeito, atingindo 
o uso de recursos sociais, para troca e compartilhamento de informações, como as mídias sociais da web social.

Além do uso dos recursos tradicionais de comunicação, foi verificado que das 16 bibliotecas centrais ou sistema de bibliotecas federais, 5 já utilizam o facebook para interagir e compartilhar informações com os seus usuários, 6 entre as 16 bibliotecas universitárias federais usam o twitter (Gráfico 3). Realizando o cruzamento entre as bibliotecas centrais ou sistema de bibliotecas federais que utilizam o facebook e twitter chegou-se ao número de 4 bibliotecas que fazem uso dos dois dispositivos de comunicação da web social. Apesar dos números apresentados no que concerne ao uso dos dispositivos de comunicação da web social não corresponderem nem a $50 \%$ do total das bibliotecas investigadas, porém, apontam para uma tendência em expansão para a realidade das bibliotecas universitárias brasileiras.

Gráfico 3- Recursos de comunicação da web social utilizados pelas bibliotecas centrais ou sistema de bibliotecas federais e estaduais

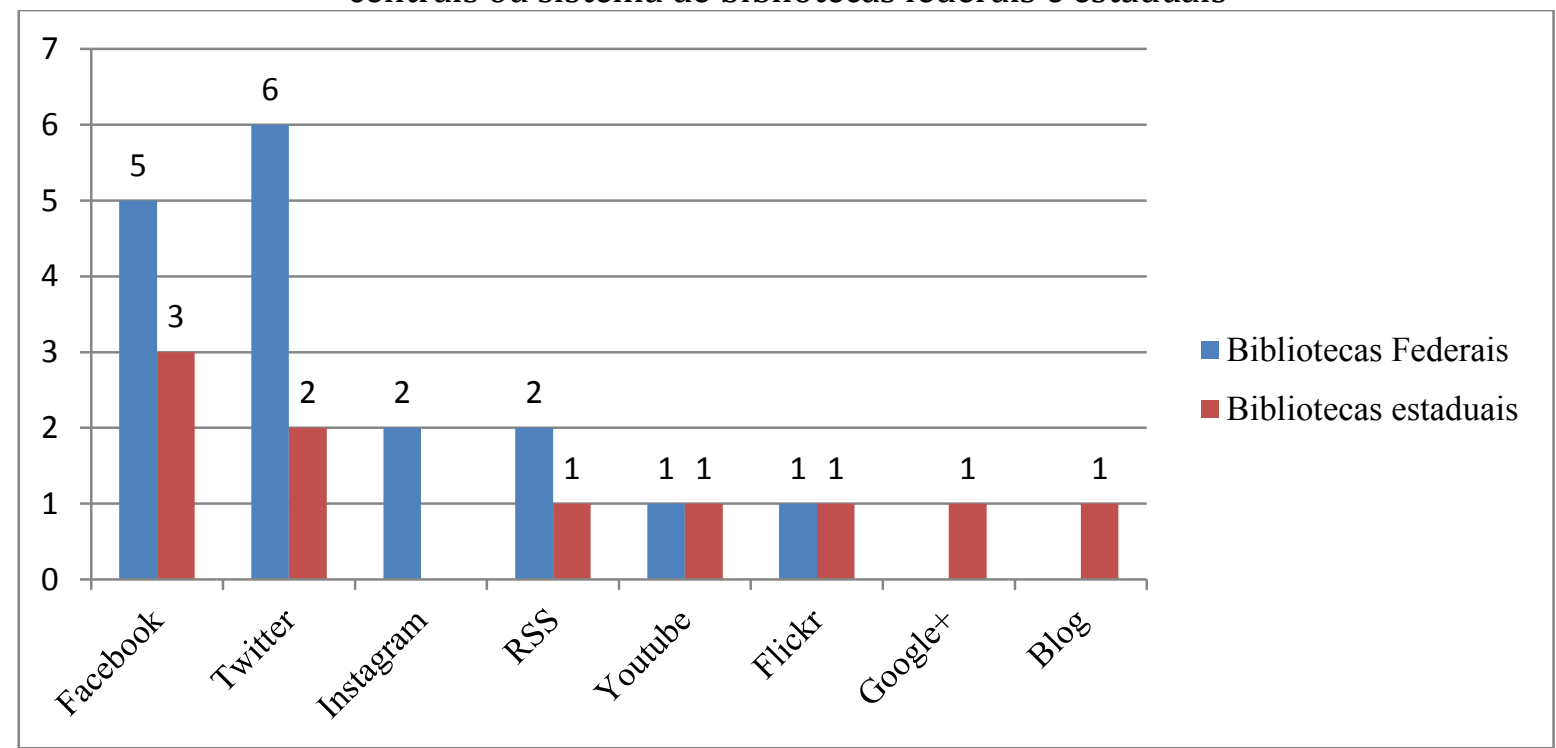

Fonte: Dados da pesquisa.

Outros dispositivos da web social foram identificados, a exemplo do instagram, o RSS, o youtube e o flickr. Contudo, são ocorrências pontuais quando comparado ao facebook e twitter.

Conforme indica o Gráfico 3, no âmbito das bibliotecas centrais ou sistema de bibliotecas estaduais o uso dos dispositivos de comunicação da web social aparece, mas, de forma ainda tímida. Das 14 bibliotecas analisadas nesse subgrupo, apenas 3 fazem uso do facebook e dentro ainda desse subgrupo duas utilizam também o twitter. 
Analisando mais detalhadamente as bibliotecas centrais ou sistema de bibliotecas estaduais depreende-se que as bibliotecas que já se encontram engajadas no uso dos dispositivos de comunicação da web social são as mesmas que já avançaram no uso dos recursos tradicionais de comunicação disponibilizados aos usuários, a exemplo do e-mail e telefone, o que nos leva a inferir que há uma relação necessária, contudo não obrigatória entre o uso dos recursos tradicionais de comunicação e os dispositivos de comunicação da web social nesse subgrupo de bibliotecas universitárias estudado.

Torna-se relevante destacar que quando os bibliotecários disponibilizam os recursos da web social, segundo Blattmann e Silva (2007) e Curty (2008) possibilitam a oportunidade dos sujeitos colaborarem e se envolverem mais intensamente com a criação, o acesso, a organização e a disseminação da informação, como também de fomentar, no ambiente virtual da biblioteca universitária, a ampliação de debates, compartilhamento de informações, entre outras atividades que promovam a interação entre os sujeitos e deles com a informação e a biblioteca.

Quanto ao segundo objetivo específico desta pesquisa consistiu em identificar se existem e quais os serviços disponibilizados aos usuários por meio dos websites das bibliotecas universitárias. Para apresentação dos dados relativos a este objetivo específico foi necessário subdividi-lo em dois grupos, sendo o primeiro relativo ao conjunto de serviços gerais online ofertados pelas bibliotecas universitárias e o segundo, aqueles voltados para a educação de usuários.

Das 16 bibliotecas centrais ou sistema de bibliotecas federais pesquisadas, todas oferecerem o serviço de consulta ao catálogo online da biblioteca, permitindo assim ao usuário verificar sobre a existência e condições de empréstimo de itens informacionais. 0 segundo serviço ofertado entre as bibliotecas universitárias federais é informes/notícias, presente em 10 das 16 bibliotecas, sendo estas notícias as mais diversas, desde avisos sobre horários de funcionamento, abertura de inscrição para treinamentos de usuário, desenvolvimento de projetos e pesquisas, conforme apresentado no Gráfico 4. 
Gráfico 4 - Serviços oferecidos pelas bibliotecas centrais ou sistema de bibliotecas federais e estaduais

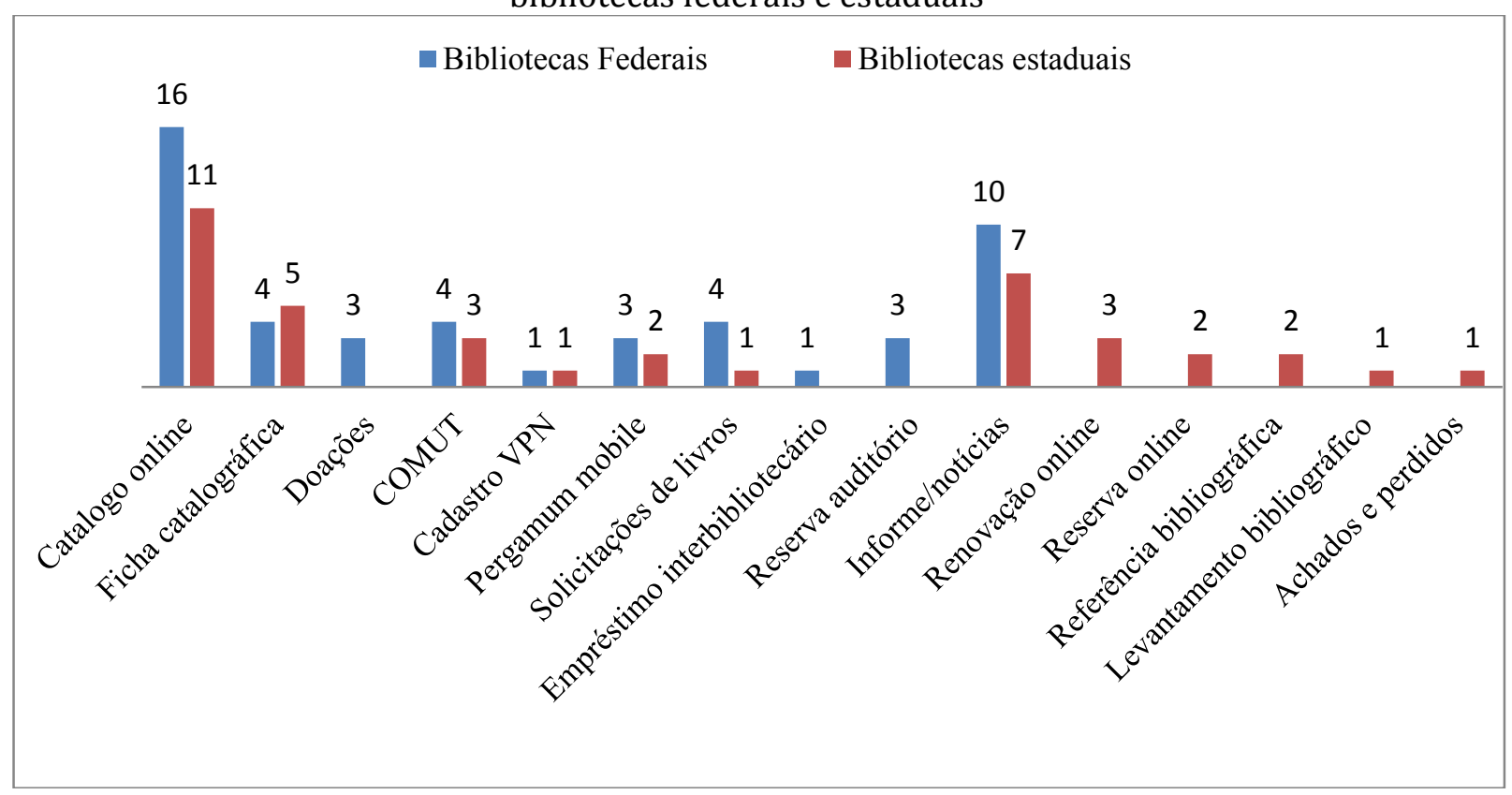

Fonte: Dados da pesquisa.

Os demais serviços ofertados aos usuários são relativos a informações para confecção de ficha catalográfica, COMUT e solicitação de livros para compra por parte das bibliotecas, sendo estes serviços citados em 4 das 16 bibliotecas analisadas. Outros serviços aparecem nos websites ou páginas das bibliotecas centrais ou sistema de bibliotecas federais, contudo em menor número, como informações relativas à reserva de auditórios para as bibliotecas que dispõem desse espaço, orientações e disposição de formulários para aqueles que têm interesse em realizar doações de itens informacionais às bibliotecas e o Pergamum Móbile para uso em aparelhos celulares.

Nas bibliotecas centrais ou sistema de bibliotecas estaduais, o serviço que apresentou maior ocorrência para este grupo foi o Catálogo online, constando em 11 das 14 bibliotecas pesquisadas, conforme indica o Gráfico 4. Contudo, observa-se que dessas 14 bibliotecas estaduais 3 delas não possuem ou possuíam website ou página no período em que fora realizado o levantamento de dados desta pesquisa, de acordo com o Gráfico 1, o que coloca as bibliotecas centrais ou sistema de bibliotecas estaduais e federais em situação similar quanto a disposição desse serviço ao usuário, ou seja, todas as bibliotecas federais e estaduais que possuem um website ou página, também disponibilizam a consulta ao Catálogo online.

Seguindo ainda uma tendência visualizada nas bibliotecas federais, os informe/notícias aparecem em 7 das 14 bibliotecas estaduais estudadas, sendo estes 
informes não somente um serviço. Constitui-se também, em um recurso de comunicação unilateral estabelecida entre as bibliotecas e seus usuários, pois, muitas dessas notícias estão relacionadas ao funcionamento das bibliotecas, ocorrência de eventos técnicocientíficos e divulgação de treinamentos.

A ficha catalográfica é o terceiro serviço mais frequente nas bibliotecas centrais ou sistema de bibliotecas estaduais (presente em 5 websites). Para algumas bibliotecas, esse serviço online restringe-se ao fornecimento de contatos de telefone e $e$-mail para que os usuários possam encaminhar os seus pedidos de ficha catalográfica, enquanto para outras, há a disponibilização desse serviço propriamente dito, através de formulário de software ou aplicativo criado para esta finalidade.

Mesmo diante da disponibilização na web de diversos textos acadêmico-científicos, o Programa de Comutação Bibliográfica (COMUT) ainda é presente tanto nas bibliotecas centrais ou sistema de bibliotecas estaduais, estando em 3 das 14 bibliotecas estudadas. O serviço de renovação online também é citado em 3 das bibliotecas, cabendo ressaltar que ele aparece como um serviço a parte, e não como uma das funcionalidades dos softwares de gerenciamento de acervo.

Demais serviços foram encontrados nas bibliotecas centrais ou sistema de bibliotecas estaduais, como a reserva online, orientação para a construção de referências bibliográficas, solicitação de livros e achados e perdidos, destacando-se entre estes o serviço de referência bibliográfica no qual é disponibilizado ao usuário o "software More" que auxilia na organização dos dados bibliográficos das obras pesquisadas para geração de referências.

Os serviços online voltados para a educação de usuários já figuram nos websites ou páginas das bibliotecas centrais ou sistema de bibliotecas federais e são de grande valia, pois eles são pensados e disponibilizados visando, sobretudo, o desenvolvimento da autonomia dos usuários no uso dos recursos informacionais das bibliotecas. Nesse sentido, ainda como se pode constatar no Gráfico 5, a orientação para uso das normas da Associação Brasileira de Normas Técnicas (ABNT) foi identificada em 6 das 16 bibliotecas federais estudadas. 
Gráfico 5 - Serviços voltados para educação de usuários nas bibliotecas centrais ou sistema de bibliotecas federais e estaduais

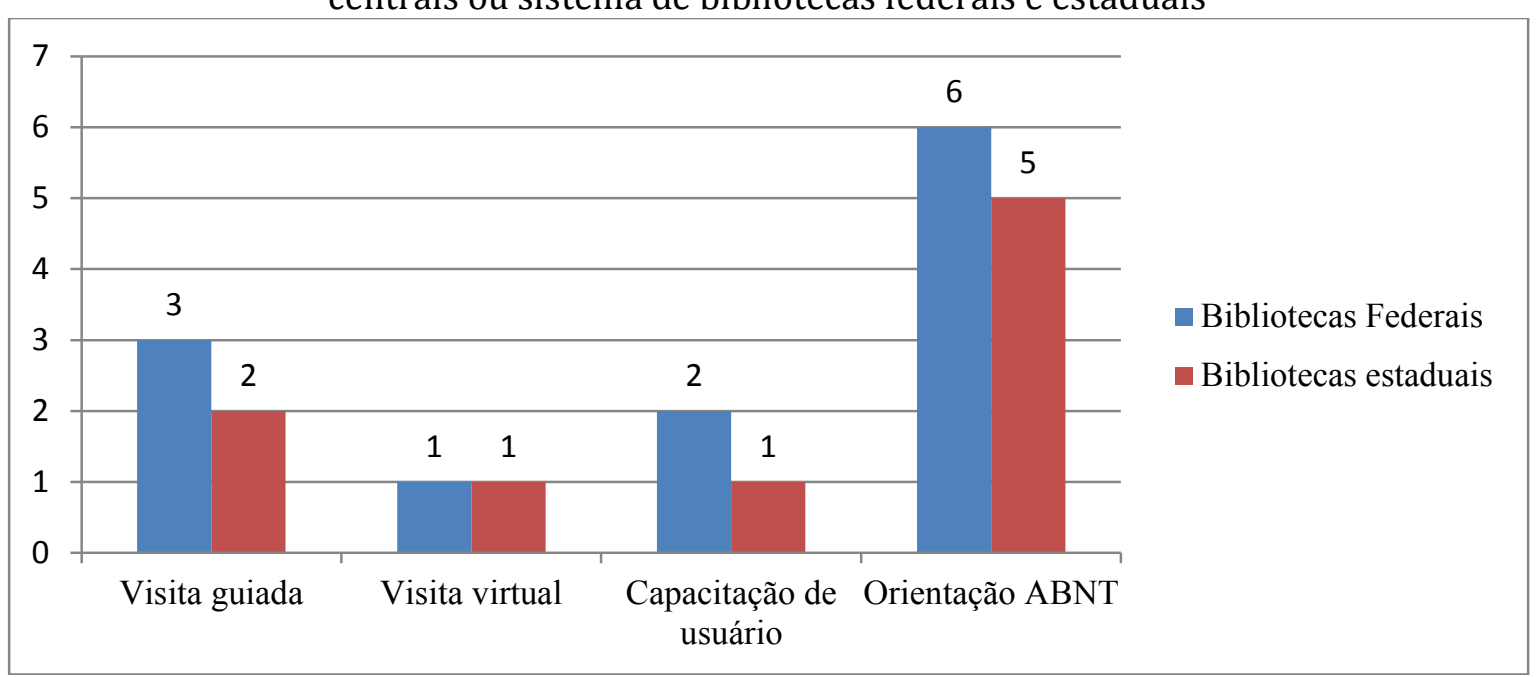

Fonte: Dados da pesquisa.

O segundo serviço disponibilizado aos usuários refere-se à solicitação à biblioteca de "visitas guiadas" ou "visitas dirigidas" (presente em 3 websites), que ocorrem mediante pedido realizado por um professor ou grupo de usuários, estes terão a oportunidade de conhecer os diversos setores das bibliotecas, seus serviços e a demonstração de algumas atividades realizadas internamente, também voltadas para pesquisa e aprendizagem.

Outros serviços voltados para a educação de usuários foram identificados nos websites ou páginas e constam em 2 das 16 bibliotecas estudadas, sendo estes a capacitação de usuário, que compreende o uso das bases de dados nacionais e internacionais e uso do acervo da instituição. Além da visita virtual, que apesar de ter sido verificado apenas em uma das bibliotecas estudadas, é citada pela inovação nos serviços de orientação ao usuário.

Dos serviços online voltados à educação de usuários oferecidos pelas bibliotecas centrais ou sistema de bibliotecas estaduais verificou-se que a orientação para o uso das normas da ABNT é presente em 5 das 14 bibliotecas estaduais, conforme indica o Gráfico 5. Esse serviço também foi o que obteve maior frequência entre as bibliotecas federais no que se refere à educação de usuários, o que leva a inferir que há uma demanda constante por este serviço, visto que algumas bibliotecas, inclusive, desenvolveram tutoriais e manuais visando atender essa necessidade dos usuários.

A visita guiada configurou-se em 2 das 14 bibliotecas centrais ou sistema de bibliotecas estaduais estudadas, enquanto que a capacitação de usuário em apenas 1 biblioteca. Esses números se aproximam daqueles encontrados nas bibliotecas federais, 
entretanto, como ainda sua expressividade é tímida, leva-nos a inferir que os serviços que envolvem uma mediação direta com o usuário ainda não são desenvolvidos ou não foram divulgados nos websites ou páginas das bibliotecas federais e estaduais.

A partir desse resultado, pode-se constatar que os bibliotecários precisam ressignificar e fortalecer as atividades de mediação direta da informação, conforme apresentado por Almeida Júnior (2015), que tem como base a comunicação mais direta com o usuário, atividades que potencializam mais ativamente o sujeito na construção e desenvolvimento de habilidades e competências informacionais. Assim, é indispensável que o bibliotecário desenvolva junto à comunidade acadêmica práticas voltadas não apenas ao acesso, busca e utilização dos dispositivos informacionais, mas que promova ações de aprendizagem informacional, conforme denominadas por Perroti e Verdini (2008), como a capacitação, que pode potencializar a aprendizagem, a competência e a autonomia em informação pelos sujeitos, favorecendo que esses alcancem o protagonismo social.

O terceiro objetivo específico desta pesquisa consistiu em identificar se existem links ou informações que aproximem e/ou auxiliem os usuários para o acesso e uso às fontes de informação. Os resultados obtidos apresentam uma diversidade de links e informações que são disponibilizadas pelas bibliotecas centrais ou sistema de bibliotecas federais, dentre estes, o acesso ao Portal de Periódicos da CAPES foi identificado em 13 dos 16 websites ou páginas das bibliotecas analisadas, como pode ser visualizado no Gráfico 6.

Gráfico 6 - Links ou informações relativas a fontes de informação nas bibliotecas centrais ou sistema de bibliotecas federais e estaduais

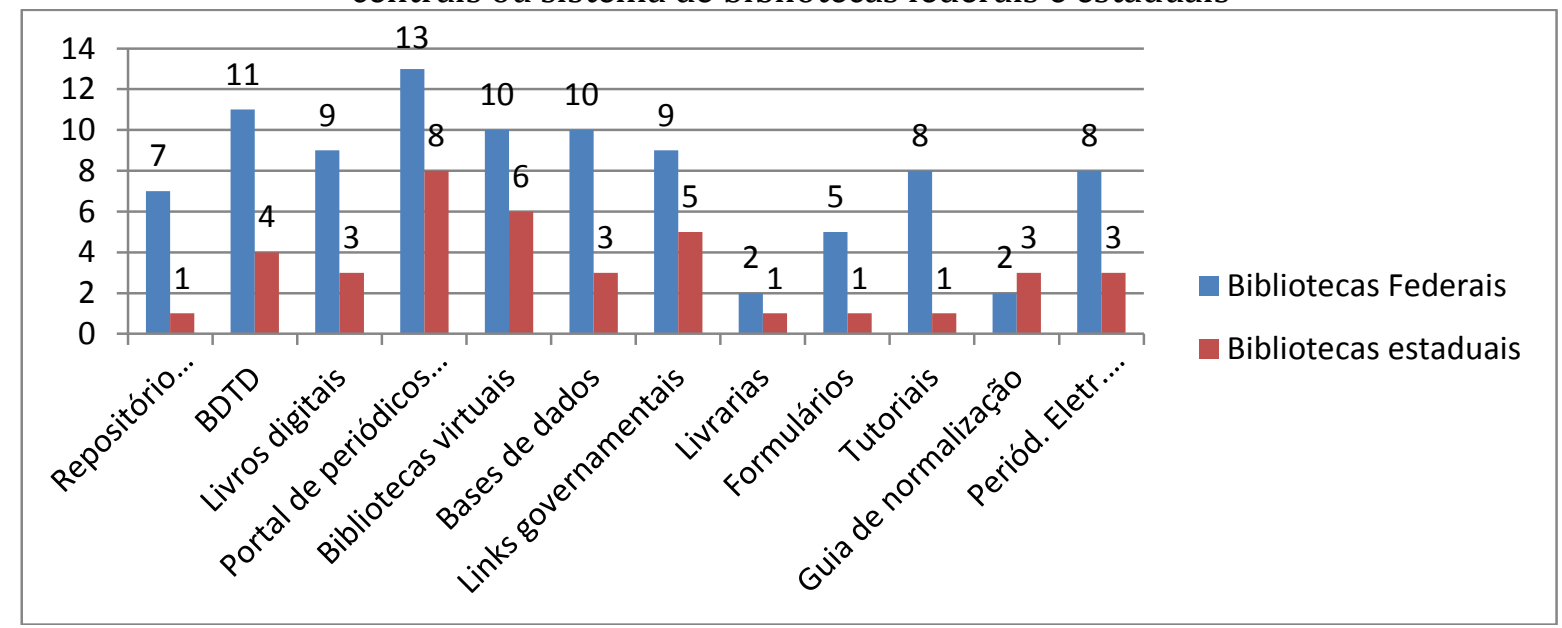

Fonte: Dados da pesquisa. 
O Banco Digital de Teses e Dissertações (BDTD) é o segundo serviço com maior ocorrência nos websites (11 das 16 bibliotecas), o que denota uma preocupação das bibliotecas centrais ou sistema de bibliotecas federais com a visibilidade da produção acadêmica institucional. Aliada a preocupação com o acesso à produção acadêmica local, muitas bibliotecas disponibilizam o acesso a bibliotecas virtuais e bases de dados, sendo identificada essa questão em 10 das 16 bibliotecas federais.

O livro digital já é uma realidade para muitas bibliotecas, principalmente as universitárias, sendo verificado o acesso a esses livros, local e remotamente, em 9 das bibliotecas analisadas, assim como a presença de links governamentais diversos, de acordo o Gráfico 6. Outra fonte de informação também encontrada nessas bibliotecas dizem respeito aos periódicos eletrônicos institucional, que estão ligados aos programas de pós-graduação locais, aparecendo em 8 das bibliotecas federais. Com essa mesma incidência estão os tutorias, que são relacionados às práticas cotidianas das bibliotecas no que concerne à orientação do usuário, como o acesso a base de dados e acervo, renovação de empréstimos, uso de normas, e-books e outros.

Quanto à identificação de Repositório Institucional (RI) foi encontrado em 7 das bibliotecas federais analisadas. O RI é uma importante fonte de informação, com função similar ao BDTD, porém com uma abrangência quanto ao tipo de documento que pode ser armazenado, inclusive em algumas instituições o RI absorveu o BDTD. Assim, pela relevância do RI, por permitir o acesso às distintas fontes de informação geradas pela instituição e por representar a preservação da memória desta, a biblioteca deveria ter uma atenção quanto à disponibilização e promoção deste recurso.

Nas bibliotecas centrais ou sistema de bibliotecas estaduais também foram encontrados uma diversidade de links ou informações relativas a fontes de informação, embora em um quantitativo reduzido ao comparado aos links ou informações disponibilizadas pelas bibliotecas federais. 0 acesso ao Portal de Periódicos da CAPES configurou-se como o link de maior ocorrência nas bibliotecas estaduais (8 das 14 investigadas), como observado no Gráfico 6.

As bibliotecas virtuais foram identificadas em 6 das bibliotecas estaduais, assim como, os links governamentais em 5 delas, e o BDTD em 4. Esses números são pouco expressivos, mas indicam que essas bibliotecas têm buscado, ainda que timidamente, oferecer links e informações que possam ser de interesse e venham atender as necessidades informacionais de seus usuários. 
Seguindo a frequência de ocorrência de links ou informações relativas às fontes informacionais nos websites ou páginas das bibliotecas estaduais, verificou-se que em 3 das 14 bibliotecas analisadas são disponibilizados aos usuários livros digitais, bases de dados, guia de normalização para trabalhos acadêmicos e periódicos eletrônicos institucional. Outros links ou informações foram identificados, porém destes o repositório institucional apresentou pouca ocorrência (1 biblioteca), enquanto que nas bibliotecas federais esse número foi de 7, o que indica que as bibliotecas estaduais ainda precisam percorrer um longo caminho a fim de garantir o acesso à produção acadêmica institucional uma vez que o número dos BDTD nessas bibliotecas também é pequeno.

\section{CONCLUSÃO}

A partir da análise dos resultados encontrados é possível afirmar que as bibliotecas centrais e/ou sistemas de bibliotecas das universidades federais e estaduais da Região Nordeste do Brasil têm desenvolvido os seus websites ou páginas buscando se apresentar de forma remota para os seus usuários, acentuadamente em um nível federal, e crescente para aquelas estaduais. Contudo, parte significativa desses espaços possui potencial para ampliar as ações de comunicação e de acesso à informação, mas não o realizam em sua plenitude, demandando ainda um extenso percurso para que venham alcançar a satisfação das necessidades de informação de seus usuários reais e potenciais, tanto na esfera dos serviços e recursos tradicionais, como aqueles possibilitados pela web 2.0 .

A pesquisa evidenciou que as bibliotecas universitárias federais e estaduais da Região Nordeste disponibilizam recursos de comunicação nos seus websites ou páginas, como o e-mail e número de telefone para contato. Entretanto, nas bibliotecas estaduais essa comunicação ainda se apresenta relativamente negligenciada, visto que o $e$-mail e o número de telefone são informações básicas para atender ao usuário e, no entanto, não aparece em alguns websites ou páginas, o que denota que a comunicação entre bibliotecas e usuários apresenta-se ainda deficiente.

O levantamento realizado indica que o processo de adesão aos dispositivos de comunicação próprios da web social, como o facebook, twitter, instagram, por parte das bibliotecas estudadas ainda é lento, mas a presença desses recursos indica que pouco a 
pouco elas estão se adaptando ao uso dos diferentes canais de comunicação, ofertando novos serviços e produtos, juntamente com os já existentes.

Por meio de seus websites ou páginas, essas bibliotecas têm buscado divulgar os serviços disponibilizados aos usuários, mas estes serviços ainda são, na maior parte dos casos, serviços básicos como o acesso ao Catálogo online e informes/notícias, demonstrando que essas bibliotecas carecem de apresentar de modo mais detalhado as informações que poderiam orientar mais adequadamente o usuário na busca da informação e uso de seus serviços, visto que estes não são restritos a um catálogo online ou informes diversos.

Os resultados dessa pesquisa sinalizam também alguma evolução nos serviços voltados para a educação de usuários, como as orientações relativas às normas da ABNT (seja presencial ou através de tutoriais) e até mesmo as visitas guiadas nos espaços das bibliotecas. Por outro lado, as atividades que envolvem de fato a capacitação do usuário são visivelmente menos frequentes, o que leva a inferir uma possível dificuldade do profissional da informação na prática da mediação direta da informação. Contudo, essa inferência demanda uma pesquisa mais aprofundada para que venha se confirmar.

Foi possível identificar que as bibliotecas centrais e/ou sistemas de bibliotecas das universidades federais e estaduais disponibilizam links ou informações que aproximem e/ou auxiliem os usuários para o acesso e uso às fontes de informação. Esse resultado foi bastante diversificado nas duas esferas, indicando que as bibliotecas, no geral, divulgam informações que consideram de interesse do usuário.

De maneira geral, as bibliotecas centrais e/ou sistemas de bibliotecas das universidades federais e estaduais da Região Nordeste do Brasil já se apresentam virtualmente para os seus usuários, mesmo disponibilizando poucas informações sobre os seus serviços ou atividades e, aproveitando fracamente o seu espaço virtual e os dispositivos da web para mediar o acesso, o uso e a apropriação da informação por seus usuários.

Os resultados dessa pesquisa apontam para a necessidade das bibliotecas universitárias repensarem não somente as suas atividades cotidianas, mas, sobretudo, como interagem com os seus usuários na esfera do espaço virtual, visto que este ainda se apresenta limitado, dificultando ou impossibilitando ao usuário conhecer e usufruir das potencialidades que esse ambiente bem planejado em termos de conteúdo, serviços e comunicação pode oferecer, seja no contexto das universidades, como além do espaço 
acadêmico.

\section{REFERÊNCIAS}

AGUIAR, Giseli Adornato de. Uso das ferramentas de redes sociais em bibliotecas

universitárias: um estudo exploratório na UNESP, na UNICAMP e na USP. 2012. $184 \mathrm{f}$.

Dissertação (Mestrado) - Universidade de São Paulo, São Paulo, 2012. Orientador: José Fernando Modesto da Silva.

ALMEIDA JÚNIOR, Oswaldo Francisco de. Mediação da informação: um conceito atualizado. In: BORTOLIN, Sueli; SANTOS NETO, João Arlindo dos; SILVA, Rovilson José da. (Orgs.). Mediação oral da informação e da leitura. Londrina: ABECIN, 2015.

BLATTMANN, Ursula; SILVA, Fabiano Couto Corrêa da. Colaboração e interação na web 2.0 e biblioteca 2.0. Revista ACB: Biblioteconomia em Santa Catarina, Florianópolis, v. 12, n. 2, 2007. Disponível em:< http://revista.acbsc.org.br/index.php/racb/article/view/530/664> Acesso em: 20 set. 2009.

CAREGNATO, Sônia Elisa. O desenvolvimento de habilidades informacionais: o papel das bibliotecas universitárias no contexto da informação digital em rede. Revista Biblioteconomia \& Comunicação, Porto Alegre, v. 8, p. 47-55, jan./dez. 2000. Disponível em: <http://eprints.rclis.org/11663/1/artigoRBC.pdf>. Acesso em: 7 nov. 2014.

CURTY, Renata Gonçalves. Web 2.0: Plataforma para o conhecimento coletivo. In: TOMAÉL, Maria Inês. Fontes de informação na internet. Londrina: Eduel, 2008. p. 53-78.

PERROTTI, Edmir; VERDINI, Antonia de Sousa. Estações do conhecimento: espaços e saberes informacionais. Texto apresentado para a série A aventura de conhecer. Programa Salto para o Futuro. TVE-MEC, setembro de 2008.

MELO, Lílian Lima de Siqueira; MARQUES Denílson Bezerra; PINHO, Fabio Assis. A biblioteca universitária e sua atuação frente à mutabilidade de paradigmas. InCID: R. Ci. Inf. e Doc., Ribeirão Preto, v. 5, n. 1, p. 69-89, mar./ago. 2014. Disponível em: < http://www.revistas.usp.br/incid/article/view/64069/pdf_17 >. Acesso em: 12 out. 2014.

VALENTIM, Marta Lígia Pomim. 0 moderno profissional da informação: formação e perspectiva profissional. Enc. Bibli: R. Eletr. Bibliotecon. Ci. Inf., ISSN 1518-2924, Florianópolis, Brasil, n.9, p.16-28, 2000. Disponível em:< https://periodicos.ufsc.br /index.php/eb/article/view/15182924.2000v5n9p16/5058> Acesso em: 12 jan. 2014.

VYGOTSKY, L. S. Aprendizagem e desenvolvimento intelectual. In: LEONTIEV, A et al. Psicologia e pedagogia: bases psicológicas da aprendizagem e do desenvolvimento. São Paulo: Moraes, 1991.

Recebido em: 17 de agosto de 2017

Aceito em: 22 de novembro de 2017 